Zixue Du

Xiaoxia Wen

Dayi Zhao

Zhouzhou Xu

Liang Chen

DOI: $10.21278 /$ TOF.41109

ISSN 1333-1124

eISSN 1849-1391

\title{
NUMERICAL ANALYSIS OF PARTIAL ABRASION OF THE STRADDLE-TYPE MONORAIL VEHICLE RUNNING TYRE
}

\begin{abstract}
Summary
The finite element model of the running tyre and the pre-stressed concrete (PC) track beam are created in the study. The wheel-rail contact status under the conditions such as acceleration or braking, lateral deviation, and roll is analysed. The wear law of the running tyre under the operating condition of driving on winding roads is discussed. The results show that the running tyre will unevenly wear when driving on the winding road; the smaller curve radius and the faster speed result in heavier and more uneven wear. There is a larger slip between the running tyre on the inner side of the curve and the rail surface, and this tyre has more uneven wear than the running tyre on the outer side of the curve. The research findings provide a theoretical basis for solving the problem of reducing the uneven wear of the running tyre.
\end{abstract}

Key words: $\quad$ Straddle-type monorail vehicle, Finite element method, Running tyre, Partial abrasion

\section{Introduction}

The travelling system of a straddle-type monorail vehicle consists of the running tyre, the guide wheel, and the bogie. A tubeless radial tyre filled with nitrogen is used as the running tyre. A phenomenon of serious partial abrasion of the running tyres on the existing straddle-type monorail vehicle in Chongqing has been noted, as shown in Figure 1 (b), (c).

Researchers in China and all over the world have investigated the partial abrasion of the tyre. Through experimental investigation, Walters M.H. drew a conclusion that, among all wheel alignment parameters, the toe angle has the most profound effect on the partial abrasion and that the camber angle comes second [1]. Yamazaki believed that the main cause of tyre partial abrasion is the microcosmic slip between the tyre and the ground caused by an increase or decrease in the magnitude of the lateral force resulting in a change in the vehicle operating parameters. Huang Hai-bo studied the tyre partial abrasion mechanism in a large vehicle-tyreground system and pointed out that the fundamental cause of tyre partial abrasion is the uneven distribution of tyre sliding force and slip velocity in the tyre axial direction and 
circumferential direction [2]. The straddle-type monorail vehicle bogie structure and the automotive chassis structure are completely different. The causes of tyre partial abrasion and the tyre partial abrasion mechanism have many differences between them. The running tyre is shown in Figure 1(a). However, not much in-depth research has been done on the partial abrasion of straddle-type monorail vehicle tyres either in China or in the world. He Guan described the phenomenon of the running tyre partial abrasion. After having monitored and analysed this phenomenon for some time, he proposed some measures, but did not explain the mechanism of running tyre partial abrasion [3].

Based on the existing results of research into the tyre partial abrasion the authors of this paper made the wheel/rail contact condition the focal point of their in-depth research on the partial abrasion law pertaining to the straddle-type monorail vehicle running tyre. The research was carried out using the finite element method.
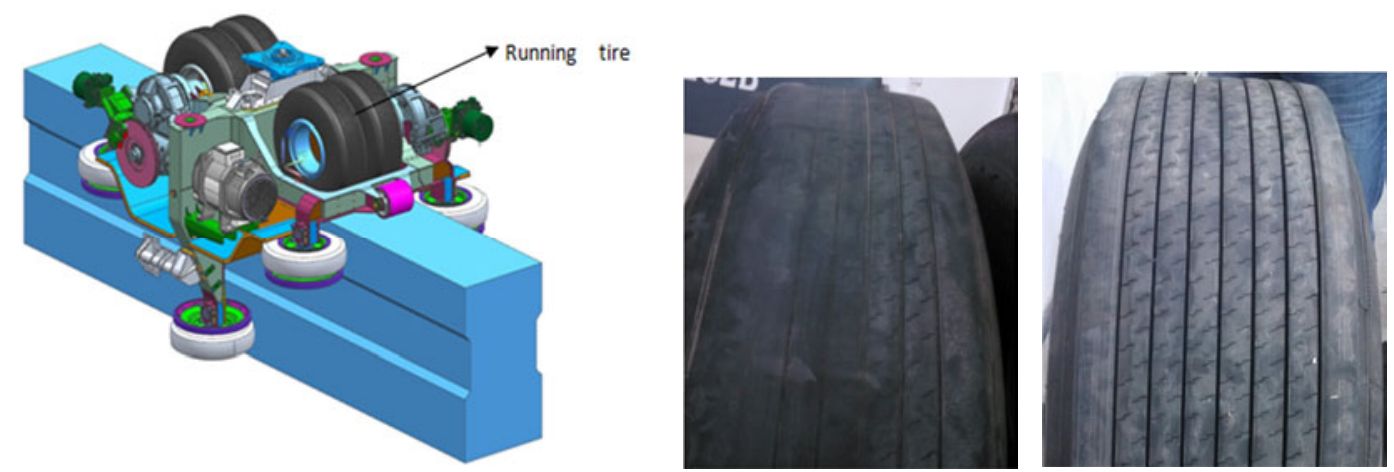

(a) a monorail bogie (b) partial abrasion (c) normal state

Fig. 1 Comparison of the running tyre state before (c) and after abrasion (b)

\section{Finite element model of the running tyre}

\subsection{A constitutive model of rubber}

The mechanical behaviour of rubber material is very complicated. In order to accurately build a finite element model of the running tyre, a precise constitutive model must be made to describe the mechanical behaviour of rubber material [3]. In this study, the Mooney-Rivlin model is used; it is expressed as

$$
U=\sum_{i+j=1}^{N} C_{i j}\left(\bar{I}_{1}-3\right)^{i}\left(\bar{I}_{2}-3\right)^{j}
$$

where $U$ is the strain energy; $N$ is material parameter, represents polynomial; $C_{i j}$ is the material parameter; $\bar{I}_{1}$ and $\bar{I}_{2}$ are the twist measurement materials. To simplify the model, make $N=1$; thus, the following expression is obtained:

$$
U=C_{10}\left(\bar{I}_{1}-3\right)+C_{01}\left(\bar{I}_{2}-3\right)
$$

$C_{10}$ and $C_{01}$ are the coefficients in the Mooney-Rivlin model. In order to confirm $\mathrm{C}_{10}$ and $\mathrm{C}_{01}$ in the Mooney-Rivlin model, a biaxial tensile test on rubber was done and the following relations were established:

$$
\begin{aligned}
& \sigma_{1}=\sigma_{2}, \sigma_{3}=0 \\
& \lambda_{1}=\lambda_{2}, \lambda_{3}=\frac{1}{\lambda_{1}}=\frac{1}{\lambda_{2}} .
\end{aligned}
$$

where $\lambda_{i}(i=1,2,3)$ are three main elongation ratios and $\sigma_{i}(i=1,2,3)$ are three main stresses. 
Insert formula (3) and (4) into formula (5)

$$
\begin{aligned}
& \sigma_{1}=2 \lambda_{1}\left[\frac{\partial U}{\partial I_{1}}+\left(\lambda_{2}^{2}+\lambda_{3}^{2}\right) \frac{\partial U}{\partial I_{2}}+\left(\lambda_{2} \lambda_{3}\right)^{2} \frac{\partial U}{\partial I_{3}}\right] \\
& \sigma_{2}=2 \lambda_{2}\left[\frac{\partial U}{\partial I_{1}}+\left(\lambda_{1}^{2}+\lambda_{3}^{2}\right) \frac{\partial U}{\partial I_{2}}+\left(\lambda_{1} \lambda_{3}\right)^{2} \frac{\partial U}{\partial I_{3}}\right] \\
& \sigma_{3}=2 \lambda_{3}\left[\frac{\partial U}{\partial I_{1}}+\left(\lambda_{1}^{2}+\lambda_{2}^{2}\right) \frac{\partial U}{\partial I_{2}}+\left(\lambda_{1} \lambda_{2}\right)^{2} \frac{\partial U}{\partial I_{3}}\right]
\end{aligned}
$$

Then

$$
\sigma_{1}=\sigma_{2}=2\left(\lambda_{1}-\frac{1}{\lambda_{1}^{5}}\right)\left(\frac{\partial U}{\partial I_{1}}+\lambda_{1}^{2} \frac{\partial U}{\partial I_{2}}\right)
$$

Insert formula (5) in formula (4) to get the fundamental formula confirming $C_{10}$ and $C_{01}$ in the biaxial tensile test on rubber.

$$
\frac{\sigma_{1}}{2\left(\lambda_{1}-\frac{1}{\lambda_{1}^{5}}\right)}=C_{10}+\lambda_{1}^{2} C_{01}
$$

\subsection{Tyre abrasion model}

In the finite element model it is assumed that the tyre is surrounded by a piece of ribbon, the centre of which is defined by orderly nodes which contain tread grooves. The ribbon contains all the surface of the contact between the tyre and the road, and the abrasion is shown even on the ribbon. The abrasion on the ribbon can be expressed as follows $[5,6]$ :

$$
q(t)=\frac{k}{H} \int_{\text {ribbon }} P(x, t) \gamma(x, t) \mathrm{d} A
$$

where $t$ is the time, $x$ is the current configuration position. The Euler steady-state transport analysis is used in the running tyre abrasion model; then, equation (8) can be rewritten as a formula which only depends on time:

$$
q=\frac{k}{H} \int_{s} P(s) \gamma(s) T(s) \mathrm{d} s
$$

where $s$ is the position along the streamline, $T(s)$ is the width when the ribbon is in the position of $s$. The equation is written in a form of attenuation function of the local material as follows:

$$
q=\frac{k}{H} \int_{s} h(s) T(s) \mathrm{d} s
$$

Discretize all the ribbon and make equation results equal, then we get:

$$
\sum_{i=1}^{N} h_{i} A_{i}=\frac{k}{H} \sum_{i=1}^{N} P_{i} \gamma_{i} A_{i}
$$

where $h_{i}$ is the melting rate of nodes, $A_{i}$ is the contact area of nodes. The equation shows that the width of the contact area is different when the ribbon is entering and leaving. However, in 
order to keep reasonable tyre structure after abrasion, it is assumed that the melting rate of nodes is even. Then, the following expression is obtained:

$$
h=\frac{k \sum_{i=1}^{N} P_{i} \gamma_{i} A_{i}}{H \sum_{i=1}^{N} A_{i}}
$$

It is assumed that the change on the ribbon in the transverse direction can be ignored, that is $T_{i}=T$. At the same time, the contact area is considered to be $A_{i}=T \cdot S_{i}$. Then we have:

$$
h=\frac{k \sum_{i=1}^{N} P_{i} \gamma_{i} S_{i}}{H \sum_{i=1}^{N} S_{i}}
$$

Formula (13) is the finite element model of the tyre tread abrasion used in the study, in which the abrasion direction is defined as the tread node normal. The node normal around the groove is defined as a direction which points to a node inside the groove.

\subsection{The finite element model}

A geometric profile of the running tyre is provided by a Chinese tyre manufacturer. Steel cord was modelled using the rebar element (named Rebar). Rubber material was modelled using CGAX3H and CGAX4H elements. The Mooney-Rivlin model was used to describe mechanical properties of the rubber material. The specific parameters come from the tyre manufacturer.

The rim is defined as analytically rigid. Material parameters of the PC track beam are shown in Table 1. The running tyre two-dimensional model is shown in Figure 2; the model has 791 nodes and 655 elements in total. On this basis, a running tyre three-dimensional model is created through the rotation function. Then, a wheel/rail contact finite element model is obtained by combining the three-dimensional model and the track beam model, as shown in Figure 2.

Table 1 Material parameters of the PC track beam

\begin{tabular}{|c|c|c|c|}
\hline Material parameters & Density/ $\mathrm{kg} / \mathrm{m}^{3}$ & Elastic modulus/ MPa & Poisson's ratio \\
\hline PC track beam & 2450 & 36000 & 0.2 \\
\hline
\end{tabular}

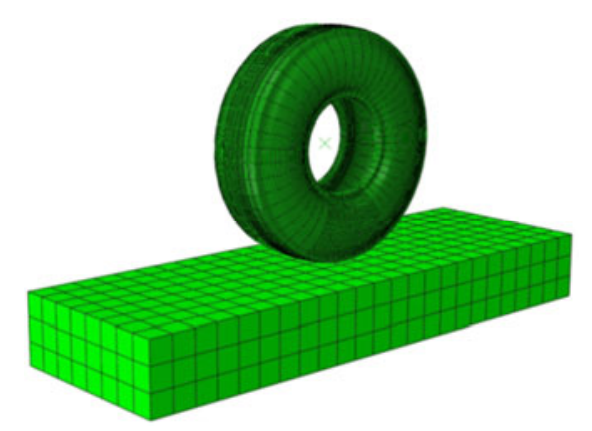

Fig. 2 There-dimensional finite element model of the wheel-rail contact

\subsection{Model verification}

The wheel/rail contact state and the tread abrasion are directly influenced by the degree of deformation caused by the tyre load [9]. Therefore, the tyre stiffness is an important index which can be used to measure the accuracy of the wheel/rail contact finite element model. The 
accuracy of the wheel/rail contact finite element model is verified by comparing the calculation results of the running tyre stiffness with the experimental results provided by the tyre manufacturer. The fitting results of the running tyre calculated stiffness are shown in Figure 3.

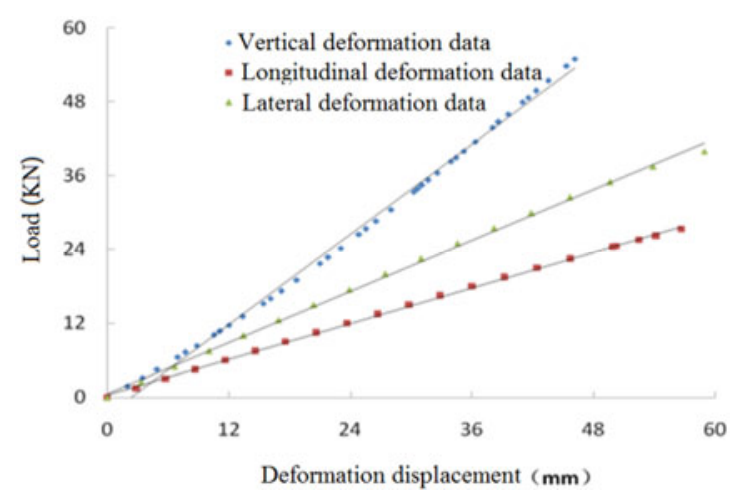

Fig. 3 Stiffness fitting curve of the running tyre

Compare the fitting results of the running tyre lateral, vertical, and longitudinal stiffness with the experimental data provided by the tyre manufacturer, as shown in Table 2.

Table 2 Comparison between the experimental data and the calculation results

\begin{tabular}{|c|c|c|c|}
\hline Parameters & Lateral stiffness/ N/mm & Vertical stiffness/ N/mm & Longitudinal stiffness/ N/mm \\
\hline Calculation results & 732600 & 1221000 & 503700 \\
\hline Experimental data & 759200 & 1286300 & 523800 \\
\hline Error & $3.51 \%$ & $5.08 \%$ & $3.04 \%$ \\
\hline
\end{tabular}

From Table 2, we can see that the error in the calculation results of the running tyre stiffness is in the allowed range relative to the experimental data. This verifies the accuracy of the wheel/rail contact finite element model.

\section{Tyre/rail contact state analysis}

\subsection{Contact state analysis under the driving/braking condition}

When a straddle-type monorail vehicle is in the driving or braking condition, there is a relative slip along the contact surface between the running tyre and the rail surface [6,7]. In order to describe the magnitude of relative slip, a concept named slip ratio is introduced and defined as follows:

$$
S_{x}=\frac{V_{x}-\omega R_{e}}{V_{x}} \times 100 \%
$$

Where $V_{x}$ is the translational velocity, $\omega$ is the rotational angular velocity, $R_{e}$ is the available radius of gyration of the running tyre.

Under the braking condition, the wheel/rail contact state has the opposite feature to the driving condition. Therefore, only the wheel/rail contact state under the driving condition is analysed here. The obtained results are shown in Figure 4. Insert the central node compressive stress from the wheel/rail contact area in the circumference direction of the running tyre; the obtained result is shown in Figure 5. From Figures 5 and 6, we can draw the following conclusions: 
1. Under the driving condition, the shape of wheel/rail contact print in the axial direction is in the state of bilateral symmetry; in the direction of heading, it is wide at the front, and narrow at the rear. This shape will be more obvious with an increase in the slip ratio.

2. Normal compressive stress is low at the front and high at the rear in the direction of heading. In the axial direction, the compressive stress exhibits a state of bilateral symmetry. The peak values of normal compressive stress occur on the left and right edges in the axial direction and in the rear area in the direction of heading.

3. With an increase in the slip ratio, the front compressive stress values in the wheel/rail contact area in the direction of heading are roughly the same, but a significant increase is noted in the rear area.

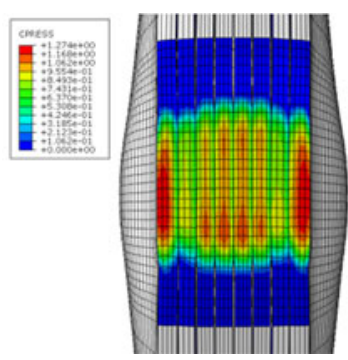

(a) slip ratio $=-10.28 \%$

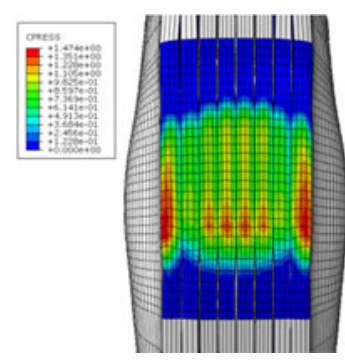

(b) slip ratio $=-10.28 \%$

Fig. 4 State of the tyre/rail contact under driving condition

(tyre rolling direction $\leftarrow$ )

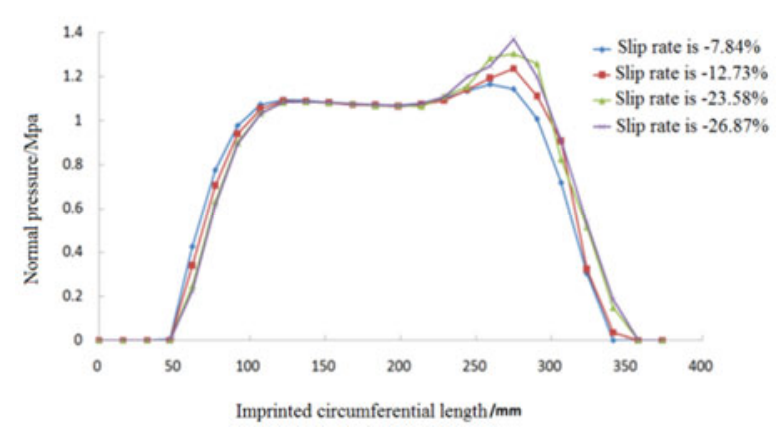

Fig. 5 Normal stress distribution curve (tyre rolling direction $\leftarrow$ )

\subsection{Contact state analysis under the side-slip condition}

Under the side-slip condition, partial abrasion can easily occur on the running tyre $[8,9]$. Keeping a longitudinal speed of $50 \mathrm{~km} / \mathrm{h}$ constant, the change in the slip angle is simulated by the lateral velocity $[10,11]$. The results of the wheel/rail contact state are shown in Figure 6 . The centre node compressive stress value obtained from the wheel/rail contact area in the axial direction is shown in Figure 7.

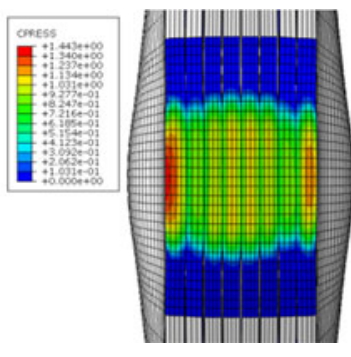

(a) slip angle $=2^{\circ}$

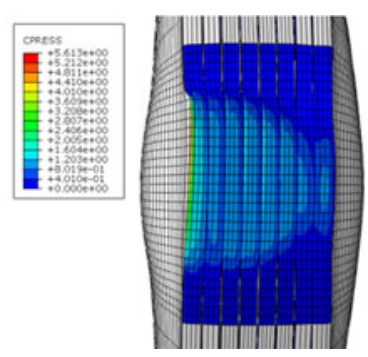

(b) slip angle $=6^{\circ}$

Fig. 6 State of the tyre/rail contact under cornering condition 


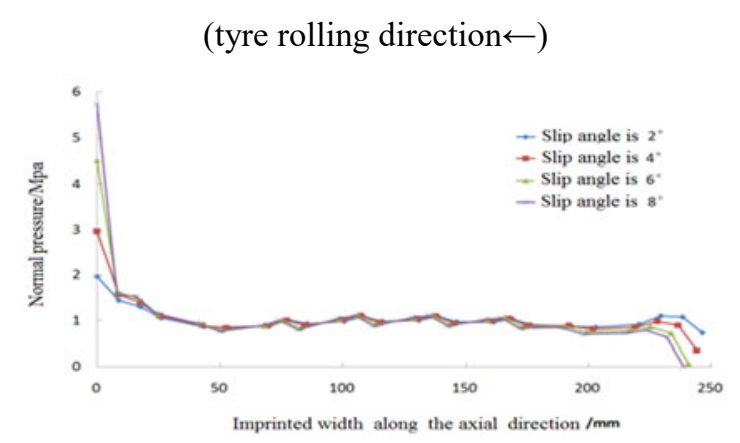

Fig. 7 Normal stress distribution curve under cornering condition (tyre cornering direction $\leftarrow$ )

From Figure 6 and Figure 7, we can conclude that with an increase in the slip angle the running tyre contact print moves gradually in the side-slip direction. Under the side-slip condition, the peak area of compressive stress occurs on the left edge in the direction of heading and the maximum normal stress in the peak area will gradually increase with an increase in the slip angle. However, the normal compressive stress on the right edge in the direction of heading will gradually decrease with an increase in the slip angle. When the slip angle is $8^{\circ}$, the right tread of the running tyre in the direction of heading is separated from the rail surface.

\subsection{Contact state analysis under camber condition}

Under camber condition, the running tyre will exhibit partial abrasion [4,5]. The wheel/rail contact state for different camber angles is shown in Figure 8 . The distribution of centre node compressive stress in the contact area in the axial direction is shown in Figure 9.

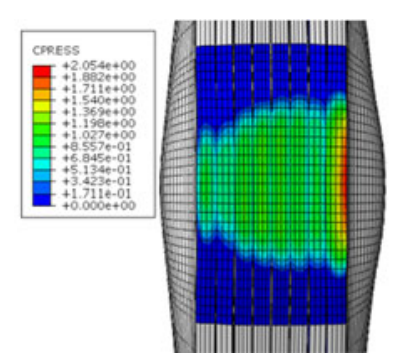

(a) camber angle $=3^{\circ}$

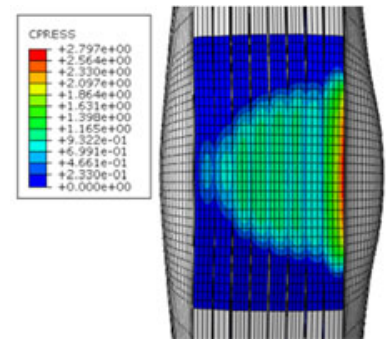

(b) camber angle $=6^{\circ}$

Fig. 8 State of the tyre/rail contact under camber condition

(tyre rolling direction $\rightarrow$ )

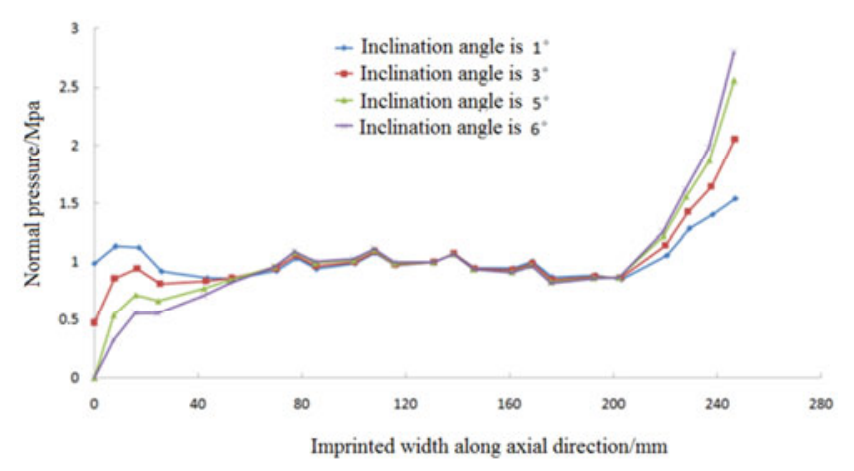

Fig. 9 Normal stress distribution curve under camber condition 
We can get the following conclusion from Figure 9 and 10:

1. The tyre/rail contact print of the running tyre moves to its camber direction gradually with an increase in the camber angle. The peak area of normal compressive stress is on the right edge in the direction of heading.

2. From Figure 8, we can see the tyre/rail contact print on the right side is larger than that on the left side. It is a symmetrical distribution state along the axis. From Figure 9, we can see that the right normal pressure is higher than the left one.

3. With an increase in the camber angle, normal pressure in the direction of heading gradually increases in the right contact area, and gradually decreases in the left contact area; in addition, the normal pressure is almost constant in the centre contact area.

\section{Contact state analysis in different turning radii}

The driving cycle of the running tyre in a curve is a condition in which the action of driving and braking is combined with the side-slip and camber conditions [12,13]. According to the analysis results about the driving/braking, side-slip, and camber conditions in the previous section of the paper, we can draw a conclusion that the partial abrasion of the running tyres of the existing straddle-type monorail vehicle in Chongqing mainly occurs in the curve running condition.

The turning radius of the existing track line in Chongqing is commonly $100 \mathrm{~m}, 150 \mathrm{~m}$, and $200 \mathrm{~m}$. Considering the performance of passing through the curve and the running stability of the straddle-type monorail vehicle, the best running speed is $36 \mathrm{~km} / \mathrm{h}, 45 \mathrm{~km} / \mathrm{h}$, and $50 \mathrm{~km} / \mathrm{h}$ when driving through the curve with a radius of $100 \mathrm{~m}, 150 \mathrm{~m}$, and $200 \mathrm{~m}$, respectively; the limiting running speed is $43 \mathrm{~km} / \mathrm{h}, 52 \mathrm{~km} / \mathrm{h}$, and $58 \mathrm{~km} / \mathrm{h}$, respectively.

A dynamic model of the straddle-type monorail vehicle was built in our laboratory. The force exerted on the running tyre in different curves at full load was analysed and the result is shown in Table 3.

Table 3 Parameters of the running tyre state

\begin{tabular}{|c|c|c|c|c|}
\hline Curve radius/ $\mathrm{m}$ & Speed/ km/h & $F_{y} / \mathrm{N}$ & Slip angle & Inclination angle \\
\hline \multirow{2}{*}{100} & 36 & 4573 & 0.351 & 3.243 \\
\cline { 2 - 5 } & 43 & 5435 & 0.492 & 3.915 \\
\hline \multirow{2}{*}{150} & 45 & 3764 & 0.414 & 3.362 \\
\cline { 2 - 5 } & 52 & 4121 & 0.587 & 4.157 \\
\hline \multirow{2}{*}{200} & 50 & 2605 & 0.329 & 2.971 \\
\cline { 2 - 5 } & 58 & 3485 & 0.468 & 3.898 \\
\hline
\end{tabular}

The magnitude and distribution of the contact compressive stress are closely related to the running tyre abrasion state. According to the force-related condition of the running tyre, the tyre/rail contact state is analysed under the tyre/rail curve running condition. The centre node compressive stress value obtained from the tyre/rail contact area in the axial direction is shown in Figure 10. 


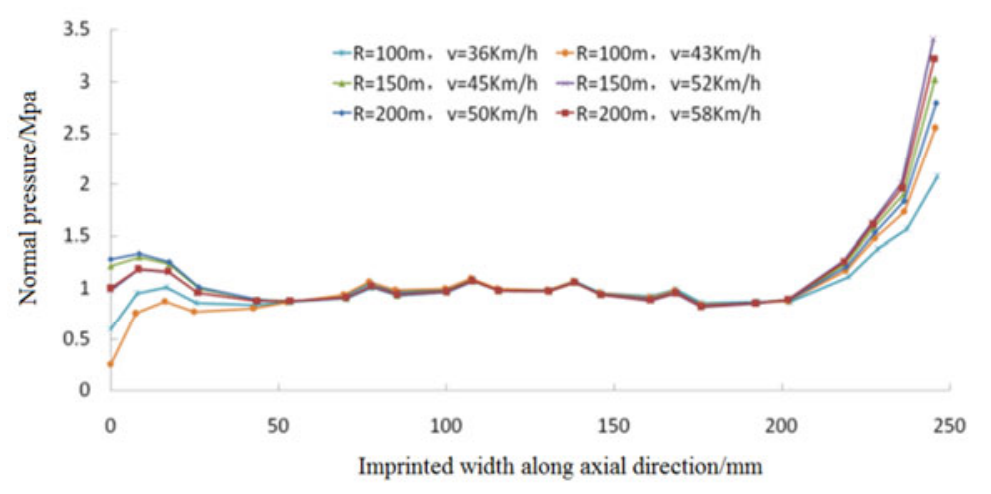

Fig. 10 Normal stress distribution curve (monorail cornering to the left)

From Figure 11 we can see that when the straddle-type monorail vehicle is running in a curve, there is a significant difference in normal stress on the left and the right sides of the wheel/rail contact area. Use formula (2), the error calculation formula [12], to represent the difference in the normal stress on the axial left and right sides of the wheel/rail contact area. The obtained results are shown in Table 4.

$$
D=\frac{P_{r}-P_{l}}{P_{r}}
$$

where $D$ is the difference in the normal stress on the axial left and right sides of the wheel/rail contact area. $P_{r}$ is the right node compressive stress and $P_{l}$ is the left node compressive stress.

Table 4 Difference in the lateral stress on the left and right sides of the contact area

\begin{tabular}{|c|c|c|}
\hline \multicolumn{2}{|c|}{ Curve driving conditions } & $\mathrm{D}$ \\
\hline \multirow{2}{*}{$R=100 \mathrm{~m}$} & $v=36 \mathrm{~km} / \mathrm{h}$ & $71.1 \%$ \\
\cline { 2 - 3 } & $v=43 \mathrm{~km} / \mathrm{h}$ & $88.9 \%$ \\
\hline \multirow{2}{*}{$R=150 \mathrm{~m}$} & $v=45 \mathrm{~km} / \mathrm{h}$ & $59.7 \%$ \\
\cline { 2 - 3 } & $v=52 \mathrm{~km} / \mathrm{h}$ & $71.2 \%$ \\
\hline \multirow{2}{*}{$R=200 \mathrm{~m}$} & $v=50 \mathrm{~km} / \mathrm{h}$ & $54.1 \%$ \\
\cline { 2 - 3 } & $v=58 \mathrm{~km} / \mathrm{h}$ & $68.9 \%$ \\
\hline
\end{tabular}

From Table 4, we can draw the following conclusions:

1. Under the condition of different turning radii, when the straddle-type monorail vehicle runs at the best running speed, the difference in the normal stress on the running tyre left and right sides will be more obvious with a decrease in the turning radius. Thus, the partial abrasion will be more serious. When the vehicle runs at the limiting speed, the conclusion will be similar, i.e. the smaller the turning radius is, the more serious the partial abrasion will be.

2. Under the conditions of the same turning radius and of safe curve passing performance of the straddle-type monorail vehicle, the faster speed entails more serious partial abrasion. This conclusion is obtained by comparing the distribution of compressive stress on the left and right sides of the running tyre at different speeds.

The straddle-type monorail vehicle bogie has no differential, so the speed of the running tyre on both sides is almost the same. Under the action of centrifugal force, the running tyre on the inner side will be "unloading", that is, the vertical load will decrease. At the same time, 
the running tyre on the outer side will be "loading". The contact state between the running tyre on both sides and the rail surface in the curve running condition at a curve radius of $150 \mathrm{~m}$ and a running speed of $45 \mathrm{~km} / \mathrm{h}$ is analysed. The results of shear stress in the wheel/rail contact area in the driving direction are shown in Figure 11.

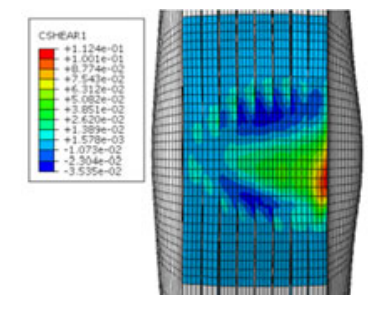

(a) inner side of the running tyre

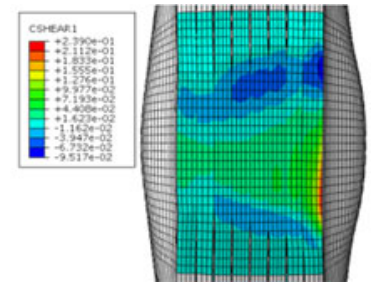

(b) outer side of the running tyre

Fig. 11 The longitudinal shear stress distribution curve

From Figure 11, we can get the following conclusions:

1. There exists larger shear stress and larger sliding possibility in the contact area between the running tyre inner side and the rail surface.

2. The distribution of shear stress in the contact area between the running tyre outer side and the rail surface is relatively centralized. And there is a phenomenon of "loading" on the outside running tyre, so it is difficult to have relative sliding.

\section{Analysis of the partial abrasion of the running tyre}

Based on the running tyre steady state calculation results, combined with the Archard tyre model, abrasion processes were simulated. Running tyres were continuously going through $100 \mathrm{~m}$ radius orbits at a speed of $36 \mathrm{~km} / \mathrm{h}$ in 1000 hours, According to the Archard tyre abrasion model, the amount of running tyre abrasion is represented by the height " $\mathrm{h}$ ". In the element calculation result, the height " $h$ " is expressed by the nodal vertical displacement of tread. The height displacement of the running tyre abrasion in the lateral direction of the tyre is shown in Figure 12. The result shows that the tread node vertical displacement height decreases from left to right, which means that the amount of running tyre abrasion decreases from left to right. The maximum amount of abrasion is located on the left side, while the minimum amount of abrasion is located on the right side. The simulation result shows that partial abrasion occurs on the running tyre.

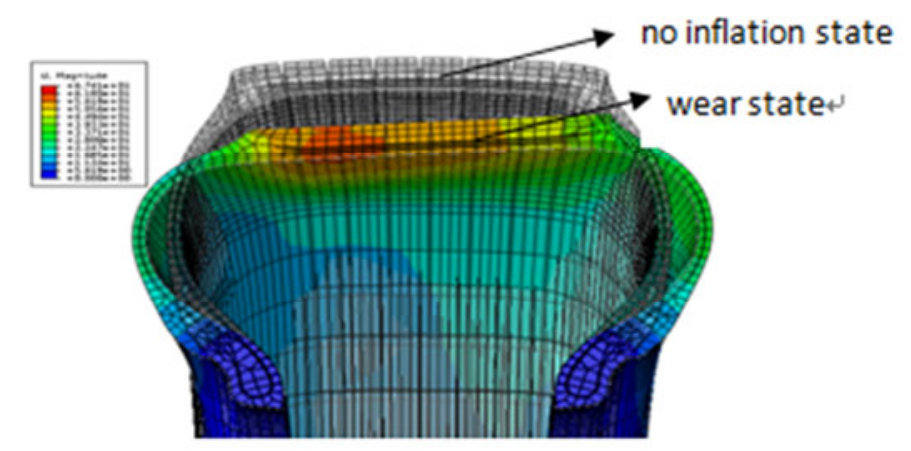

Fig. 12 Running tyre partial abrasion simulation

The lateral stress values before and after abrasion of tread were extracted. A comparison of the node displacement of tread before and after abrasion is show in Figure 13. From that figure, one can see that the maximum lateral force is reduced from $0.294848 \mathrm{MPa}$ to $0.21864 \mathrm{MPa}$. It is shown that the worn tyre would reduce the maximum lateral stress. 


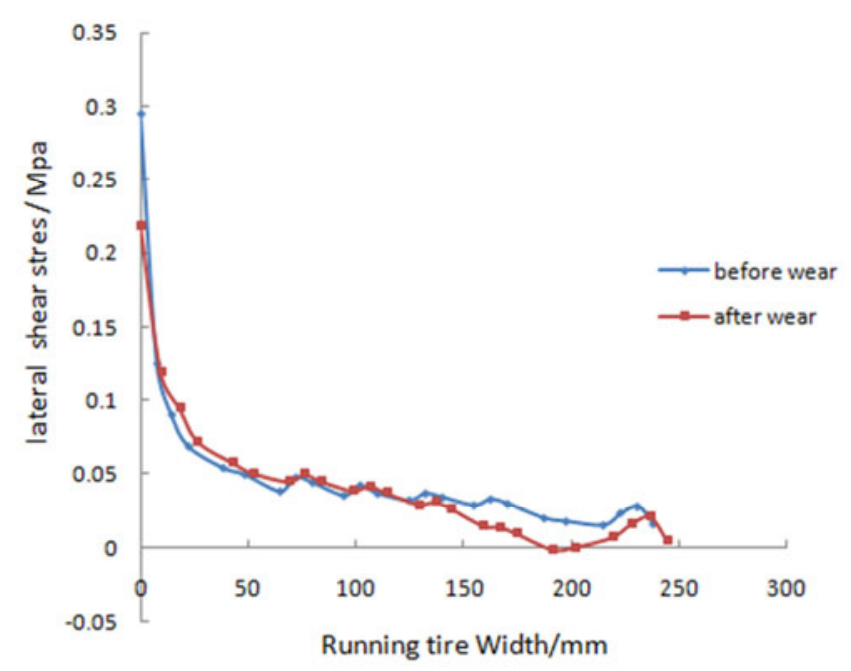

Fig. 13 Comparison of lateral stress before and after abrasion

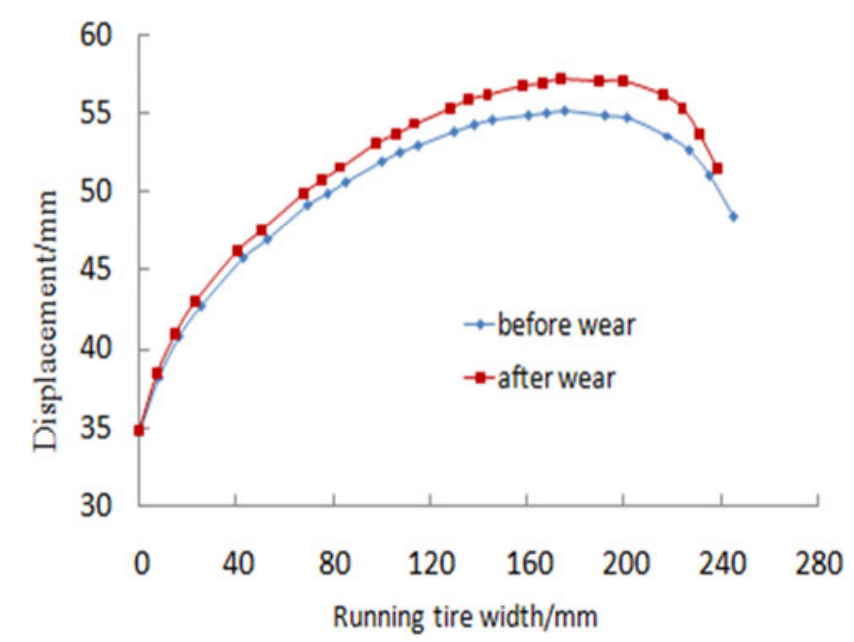

Fig. 14 Comparison of the node displacement of tread before and after abrasion

In order to observe the amount of wear, values of the node vertical displacement of tread were extracted. A comparison of node vertical displacement of tread in the lateral direction of the running tyre before and after abrasion is show in Figure 14. In this figure, the node vertical displacement of tread before wear is shown with the blue curve and the node vertical displacement of tread after wear is shown with the red curve. The radial wear is equal to the differential between the node vertical size change after wear and that before wear. The wear of the tread of the running tyre is shown in Table 5.

Table 5 Simulation error between the simulation wear and test data

\begin{tabular}{|c|c|c|c|c|c|c|}
\hline $\begin{array}{c}\text { Running tyre width/ mm } \\
\text { (from the left side to the right side) }\end{array}$ & 0 & 8 & 17 & 226 & 235 & 245 \\
\hline Before wear & 48.4694 & 51.081 & 56.1665 & 40.7424 & 38.3799 & 34.7215 \\
\hline After wear & 51.4544 & 53.6678 & 53.611 & 40.9405 & 38.2194 & 34.7215 \\
\hline Wear height/mm & 2.985 & 2.5868 & 2.6162 & 0.1981 & 0.1605 & 0 \\
\hline
\end{tabular}

In order to describe the partial abrasion degree, an evaluation index was proposed, as shown in formula (16): 


$$
e=s_{l}-s_{r}
$$

where $e$ represents the difference in the tread node vertical displacement between the left and the right sides, $s_{l}$ represents the node displacement on the left side, $s_{r}$ represents the node displacement on the right side. According to formula (16), the abrasion deviation of the running tyre is $2.985 \mathrm{~mm}$.

\section{Result verification}

The abrasion phenomenon from the simulation was compared with that of the actual running tyre continuously in operation for $36000 \mathrm{~km}$ is shown in Figure 15. The amount of the actual tyre abrasion also gradually decreases from left to right; thus, the simulation calculation results and the observed actual tyre abrasion trends are consistent with the fact that partial abrasion occurs on the running wheel.
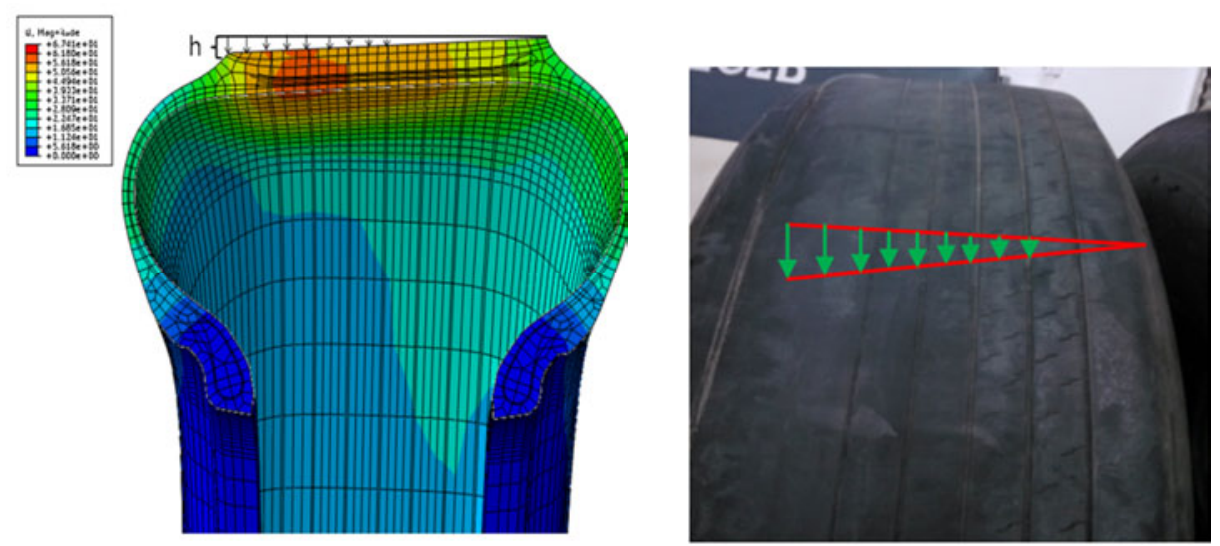

Fig. 15 Abrasion phenomenon - simulation (left) and the actual running tyre (right)

In order to verify the accuracy of the simulation analysis, the wear height of the worn tyre was tested. A comparison between the simulation data and the test data is shown in Figure 16. From that figure we can deduce that the error between the simulation data and the test data is small; the maximum error is only $8.19 \%$, as shown in Table 5 . The simulation result is reliable and the application of the simulation model for the prediction of tyre partial abrasion is feasible.

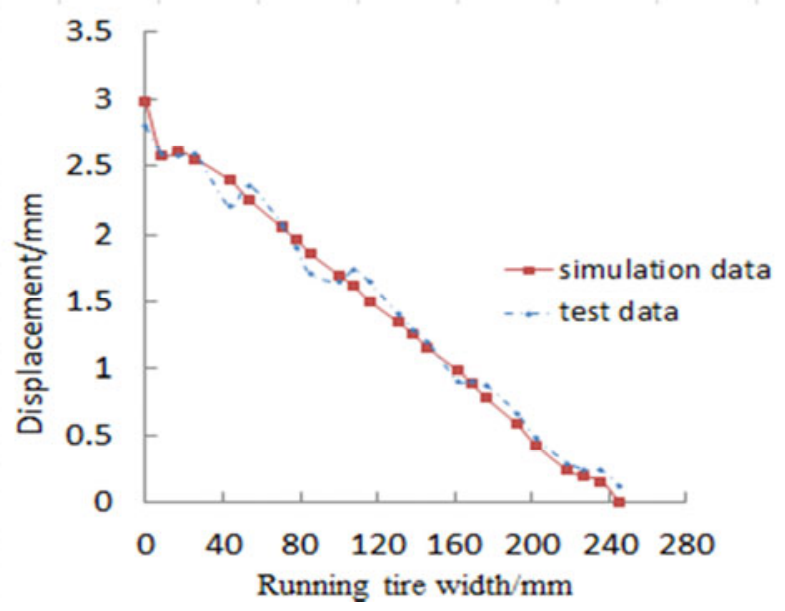

Fig. 16 Tyre abrasion - comparison between simulation results and test data 
Table 6 Comparison between wear simulation results and test data and the resulting simulation error

\begin{tabular}{|c|c|c|c|c|c|c|}
\hline $\begin{array}{c}\text { Running tire width/ mm } \\
\text { (from the left side to the right side) }\end{array}$ & 0 & 8 & 17 & 26 & 43 & 53 \\
\hline Wear height simulation data/ mm & 2.985 & 2.5868 & 2.6162 & 2.5555 & 2.3963 & 2.2543 \\
\hline Wear height test data/ mm & 2.8 & 2.6 & 2.58 & 2.59 & 2.2 & 2.36 \\
\hline error & $6.20 \%$ & $0.51 \%$ & $1.38 \%$ & $1.35 \%$ & $8.19 \%$ & $4.69 \%$ \\
\hline
\end{tabular}

\section{Conclusion}

The finite element model of the running tyre and the PC track beam was developed for the study. The wheel/rail contact state under the conditions such as acceleration, braking, sideslip, and camber is analysed. In addition, the wear law of the running tyre under the operating condition of driving on a winding road is discussed. The research findings are as follows:

1. When the running tyre is under the condition of driving/braking, there is a significant difference in the compressive stress distribution of tread contact in the direction of heading; consequently, polygonal abrasion will occur on the running tyre.

2. When the running tyre is under the condition of side-slip or camber, there is a significant difference in the compressive stress distribution of tread contact in the tyre axial direction.

3. When the running tyre is under the condition of a winding road, the partial abrasion will become more serious with a decrease in the curve radius. Under the premise of ensuring curve passing performance of the straddle-type monorail vehicle, the higher speed entails more serious partial abrasion. There will be a lager slip between the running tyre on the inner side of the curve and the rail surface, and the partial abrasion will be more serious than that on the running tyre on the outer side.

According to the law aforementioned, to establish control over the safe running of the straddle-type monorail vehicle, a "sudden start and sudden stop" running state should be avoided, and the passing speed in different turning radii should be studied and optimized. As for the design of the straddle-type monorail vehicle bogie, the installation of a differential should be considered. These methods can reduce the partial abrasion of the running tyre.

\section{Acknowledgement}

This paper belongs to Fund Project of the "National Natural Science Foundation of China" Project Name: Research on the Mechanism and Control Method of Monorail Trains Running Tires' Shoulder Wear

Project Number: 51475062

\section{REFERENCES}

[1] Zhuang Ji-de. Advanced Technology of Tire[M].Beijing: Beijing Institute Technology Press,2001.

[2] Huang Hai-bo. Research on Abnormal Wear Mechanism and Service Life Prediction for Car Tire[D].Shanghai: Tongji University,2006.

[3] He Guan. Measures against Tread Wear of Monorail Travelling Tires in Chongqing[J]. Urban Mass Transit, 2010 (6),63 67.

[4] Koorosh C. A Computer Method of Analysis for Tire Wear [J]. Journal of Testing and Evaluation. 2004.10(1): 45-57. 
[5] van der Steen R, Lopez I, Nijmeijer H. Experimental and numerical study of friction and stiffness characteristics of small rolling tires[J]. Tire Science and Technology.2011, 39(1): 5-19. DOI: $10.2346 / 1.3555134$

[6] van der Steen R, Lopez I, Nijmeijer H, et al. Experimental and numerical study of friction and braking characteristics of rolling tires[J]. Tire Science and Technology.2011, 39(2): 62-78. DOI: $10.2346 / 1.3593664$

[7] Zheng Kai-feng, Du Zi-xu. Influence of Speed and Track Radius on Passing Performance in Curve of Straddle-Type Monorail Vehicle [J]. Locomotive Electricity Transmission. 2011.05: 23-24.

[8] Lupker H, Cheli F, Braghin F et al. Numerical prediction of car tire wear [J]. Tire Science and Technology.2004, 32(3): 164-186. DOI: 10.2346/1.2186780

[9] Li Zhao. The Experimental Study and Numerical Analysis of Tread Wear Behavior[D].Hefei: University of Science and Technology of China, 2013.

[10] Zhuang Zhuo, ZHANG Fan, CEN Song, etc. ABAQUS Nonlinear Finite Element Analysis and Instance[M]. Beijing: Science Press, 2005.

[11] Wang Guo-lin, Fan Xu-feng, Jiang Hao-bin. Tire Grounding Print Study on combined action of Extraversion and Side-slip[J]. Automotive Engineering. 2004. 26(1):54-56.

[12] Ge Jin-hu, Wang Guo-lin, Ying Shi-zhou, etc. Finite Element Analysis of Radial Tire Grounding Performance with Loading[J]. Rubber Industry. 2008.55(5):309-312.

$\begin{array}{ll}\text { Submitted: } & 17.4 .2016 \\ \text { Accepted: } & 14.12 .2016\end{array}$

\author{
Zixue Du \\ Dayi Zhao \\ Institute of Urban Rail, ChongQing \\ JiaoTong University, ChongQing 400074, \\ China \\ Xiaoxia WEN \\ Zhouzhou Xu \\ Liang Chen \\ School of Electrical and Vehicle \\ Engineering, Chong Qing JiaoTong \\ University, Chongqing 400074, China \\ Email: aaadzx@163.com, \\ wenxiaoxia150@163.com
}

